
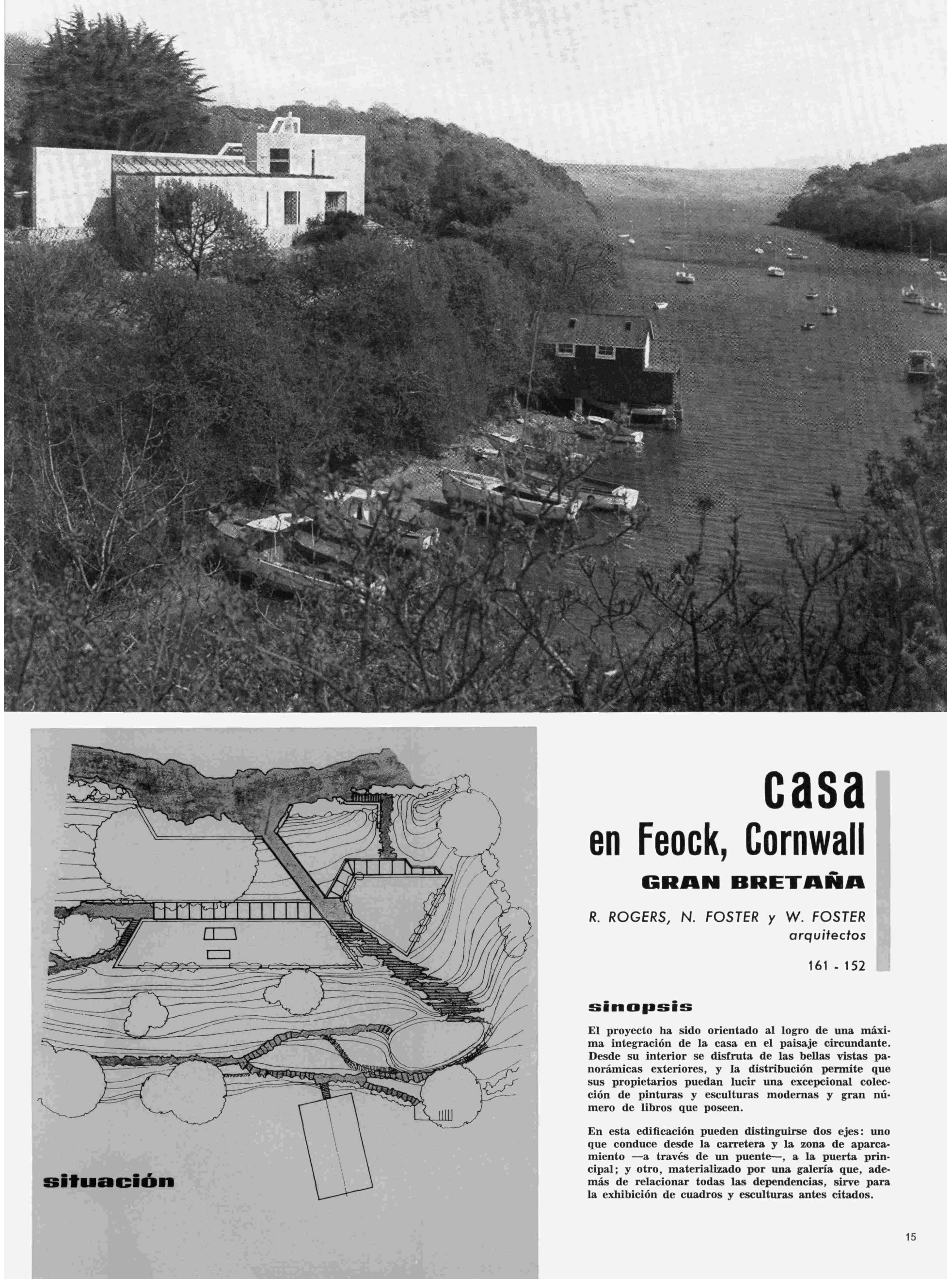

\title{
casa \\ en Feock, Cornwall GRAN BRETAÑa
}

R. ROGERS, N. FOSTER y W. FOSTER

arquitectos

$161 \cdot 152$

\section{sinopsis}

El proyecto ha sido orientado al logro de una máxima integración de la casa en el paisaje circundante. Desde su interior se disfruta de las bellas vistas panorámicas exteriores, y la distribución permite que sus propietarios puedan lucir una excepcional colección de pinturas y esculturas modernas y gran número de libros que poseen.

En esta edificación pueden distinguirse dos ejes: uno que conduce desde la carretera y la zona de aparcamiento - a través de un puente-, a la puerta principal; y otro, materializado por una galería que, además de relacionar todas las dependencias, sirve para la exhibición de cuadros y esculturas antes citados. 


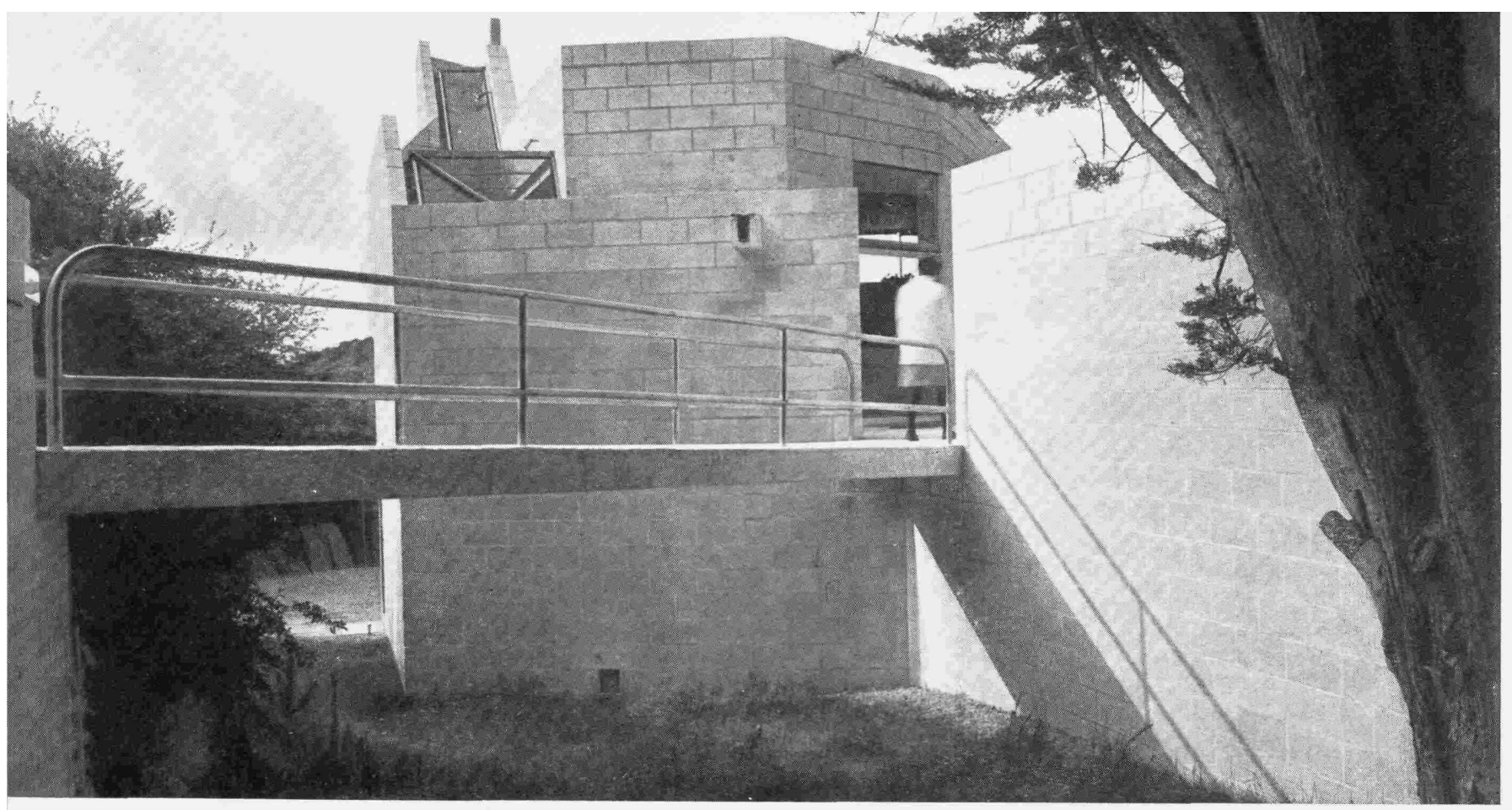

Diseñada con indiscutible acierto, satisface el programa de necesidades dado. En él figuraba que la Casa debía de constar de: un cuarto de estar, comedor, cocina, estudio, dormitorios, una «suite» para huéspedes — con entrada independiente- y taller.

Fue concebida adecuadamente para que los diferentes ambientes creados sugiriesen en los usuarios una sensación de alegría y que desde ella pudiesen gozar de la gran belleza que ofrece el paisaje exterior. Se trata de una vivienda proyectada para ser integrada en la naturaleza circundante, y cuyos interiores se han dimensionado con amplitud apropiada para la exhibición de una colección excepcional de pinturas y esculturas modernas y de gran número de libros. Se ha pensado para que el costo y trabajo de mantenimiento fueran mínimos, previendo la posibilidad de una futura ampliación.

Fue construida sobre la parte más despejada de un solar de pendiente muy pronunciada, rodeado por una carretera en su parte superior, y un embarcadero abajo, en el río. Su emplazamiento permite el disfrutar de unas bellas vistas: sobre el mar, al sur; del río y del bosque, al oeste, y dominar hacia el norte una bella vista panorámica del valle. Las vistas más interesantes de alta mar se divisan a partir de los $4 \mathrm{~m}$ de altura sobre el nivel del terreno.

En el conjunto construido se pueden apreciar dos ejes fundamentales: uno este-oeste, que conduce desde la carretera y la zona de aparcamiento, a través de un puente, a la puerta principal; con tramos de escalera que llevan al campo y, bajando, al embarcadero y al río.

El otro eje va en dirección norte-sur y adopta la forma de una galería - utilizada para la exhibición de cuadros y esculturas-, con una cubierta acristalada que le permite disponer de una homogénea iluminación cenital. Esta galería, que relaciona todas las estancias, empieza en una terraza y termina en un garaje subterráneo, en el extremo norte del emplazamiento.
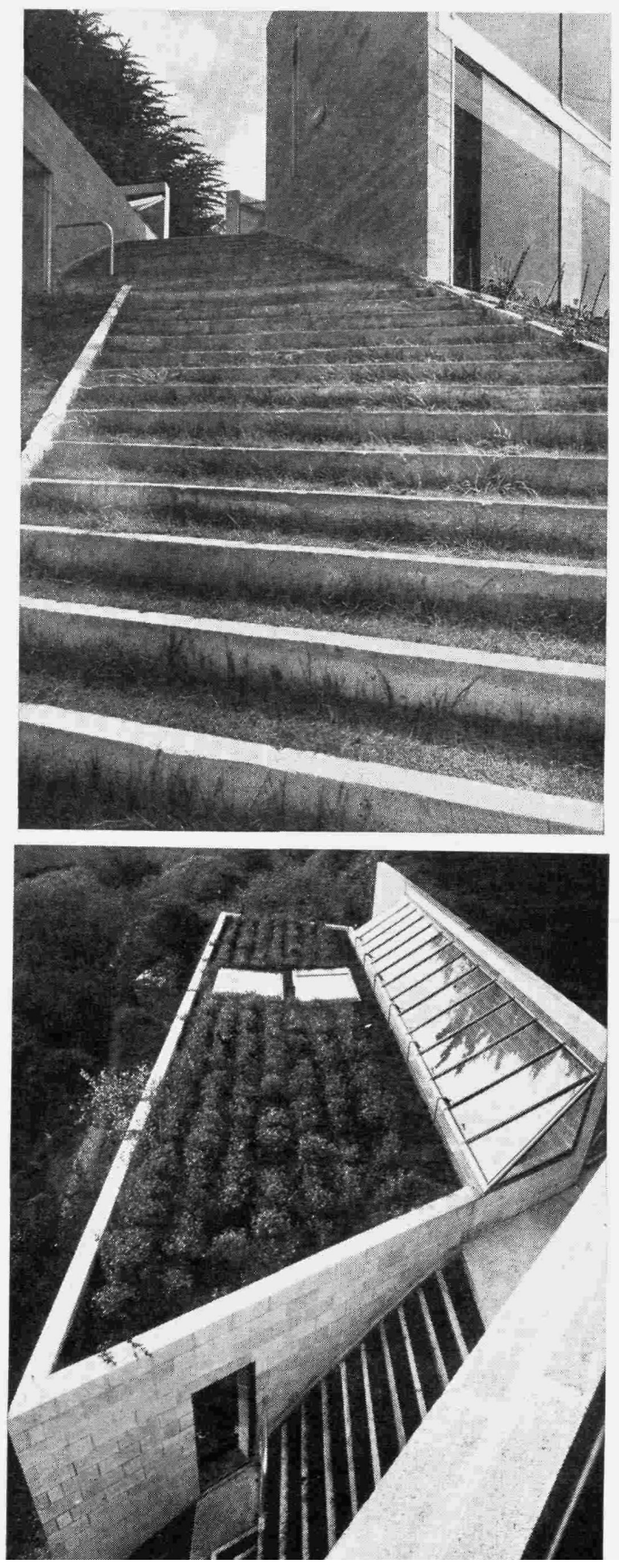


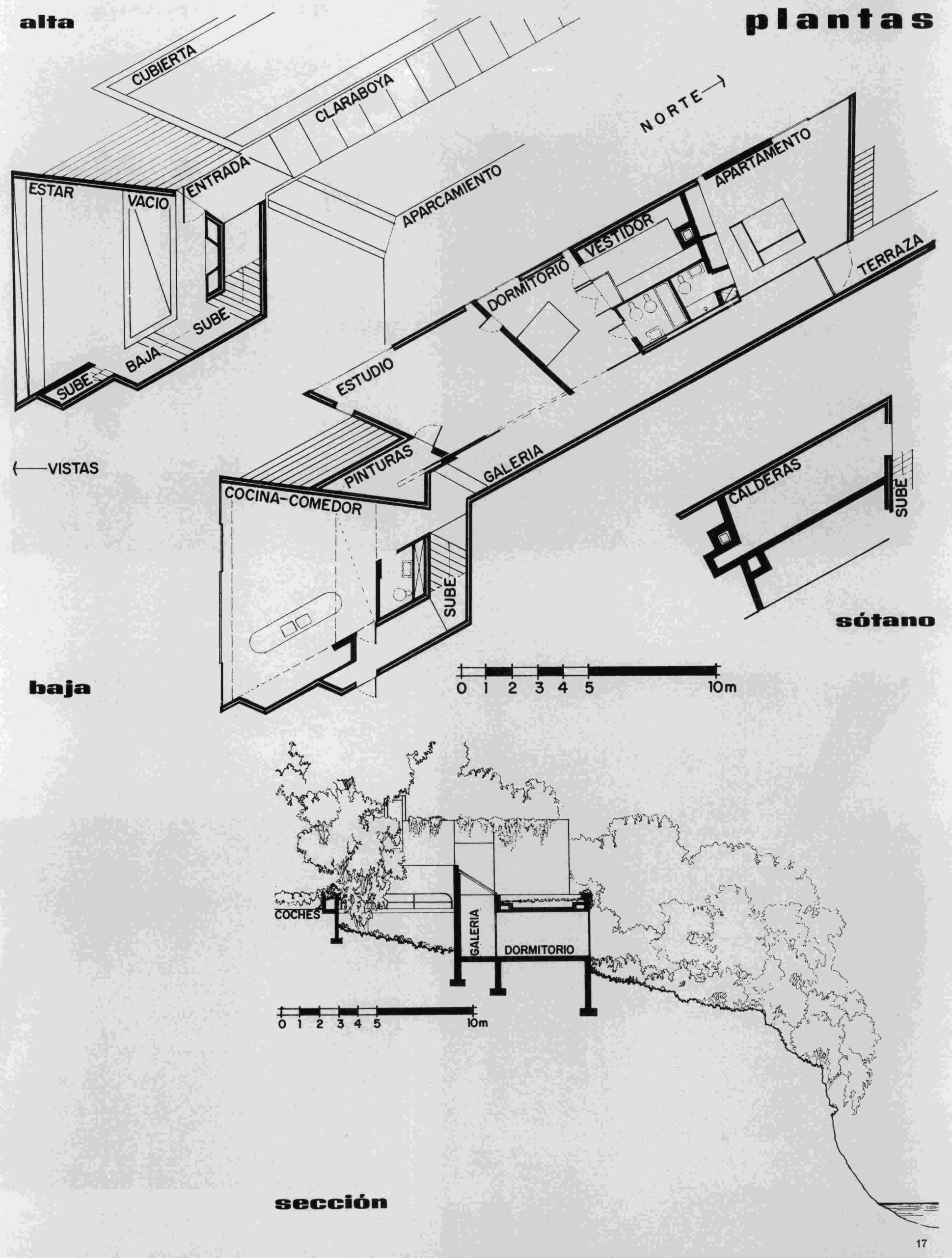




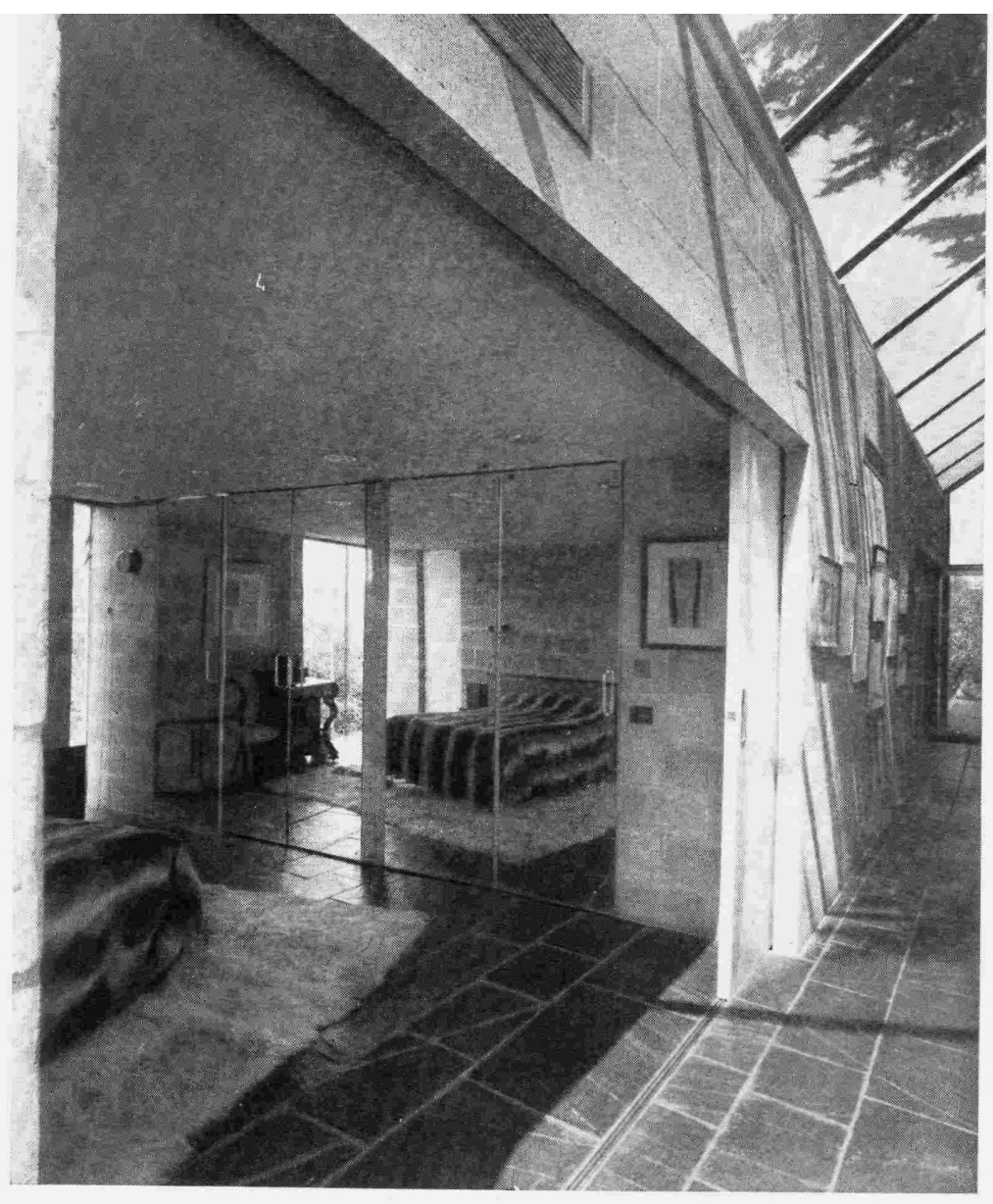

detalle e interiores
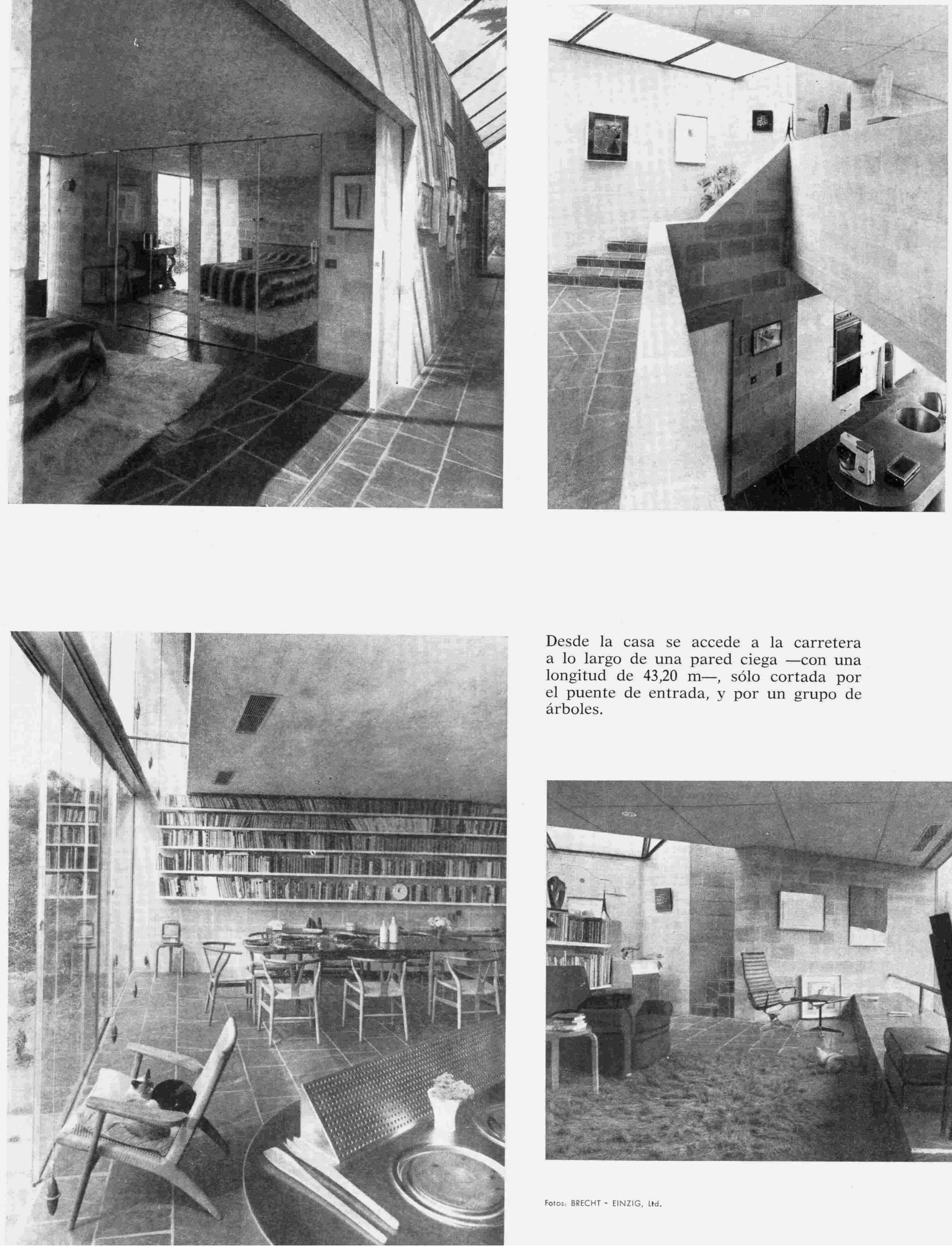

Desde la casa se accede a la carretera a lo largo de una pared ciega - con una longitud de 43,20 m-, sólo cortada por el puente de entrada, y por un grupo de árboles.

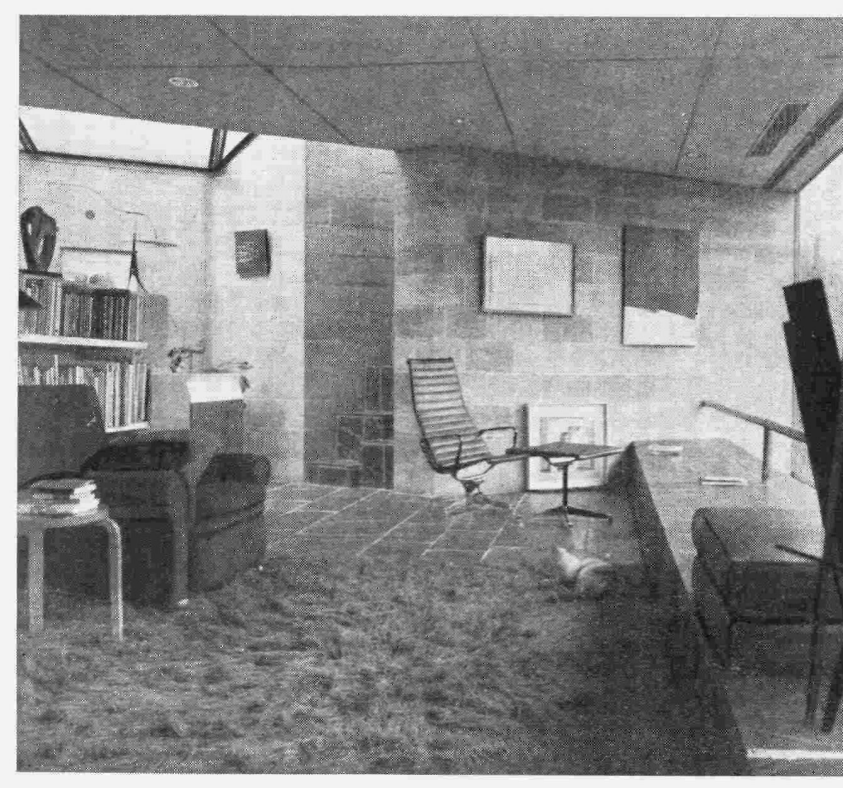

(c) Consejo Superior de Investigaciones Científicas Licencia Creative Commons 3.0 España (by-nc) 
Todas las habitaciones han sido proyectadas para vivir hacia el exterior, y las dos alas de viviendas están orientadas mirando al mar, al río y al valle.

Amplias mamparas laterales permiten acceder desde todos los cuartos «privados» a la galería, lo que además contribuye a que en todas las zonas del interior se pueda disfrutar la sensación de desahogo $\mathrm{y}$ amplitud visuales.

Para lograr un mínimo entretenimiento del edificio fueron dejados todos los materiales en su estado natural -color y textura-, excepto la ebanistería, a la que se le dio un acabado de poliuretano blanco.

Desde los tejados, enredaderas colgantes cubren toda la casa.

Respecto al entorno paisajístico, señalaremos que el solar fue replantado con arbustos silvestres, hiedra, césped y muchos árboles, de modo que exista un máximo contacto y mimetismo con la naturaleza circundante.

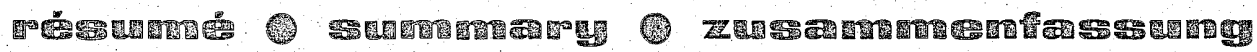

\section{Moison di Feock, Gommualles - Grande-Bretrighe}

R. Rogers, N. Foster et W. Foster, architectes

Cette maison a été conçue avec l'idée de l'incorporer au maximum au paysage environnat. De l'intérieur, ses habitants ont sous les yeux les beaux panoramas extérieurs et la distribution leur permet de mettre en valeur une collection exceptionnelle de peintures et de sculptures modernes, ainsi qu'un grand nombre de livres.

Deux axes se distinguent dans ce bâtiment: l'un qui conduit de la route et de la zone de parking —en passant par un pont - à la porte principale, et l'autre formé par une galerie qui, en plus de donner accès à toutes les pièces, sert à l'exposition des sculptures et des tableaux.

\section{Feock's House, Bommwall, Gt. Britain}

R. Rogers, N. Foster and W. Foster, architects

This project seeks to integrate the house as much as possible with the surrounding landscape. From its interior there is an excellent view of the beautiful countryside, and the inside distribution provides facilities for exhibiting a fine collection of painting and modern sculpture, as well as a large number of books, possessed by the house owners.

This building is designed round two main axes. One leads from the road and parking site, across a bridge, to the main gate; whilst the other coincides with a broad gallery, which besides connecting all the rooms, serves for the exhibition of the painting and sculptures mentioned previously.

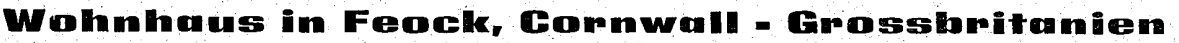

R. Roger, N. Foster und W. Foster, Architekten

Mit der Planung wurde das Ziel verfolgt, eine weitestgehende Einpassung des Hauses in die umgebende Landschaft zu erzielen. Von innen geniesst man herrliche Ausblicke; die Anordnung ermöglicht es den Bewohnern, eine aussergewöhnliche Sammlung moderner Gemälde und Skulpturen sowie zahlreiche Bücher unterzubringen.

Bei dieser Bebauung können zwei Achsen unterschieden werden: Eine führt von der Strasse und den Parkplätzen - über eine Brücke- zum Haupteingang; die andere, dargestellt durch eine Galerie, verbindet einerseits die verschiedenen Nebenräume miteinander und dient andererseits zur Ausstellung der erwähnten Gemälde und Skulpturen. 